\title{
COVID-19 psychological impact, knowledge and perceptions of healthcare professionals in Greece: A nationwide cross-sectional study
}

\author{
Myrto T. Samara, ${ }^{1,2}$ Lily E. Peppou, ${ }^{3,4}$ Theodoros V. Giannouchos, ${ }^{5}$ Ioannis Nimatoudis, ${ }^{1}$ \\ Charalampos Papageorgiou, ${ }^{3}$ Marina Economou, ${ }^{3,4}$ Kyriakos Souliotis ${ }^{6,7}$ \\ '3rd Department of Psychiatry, School of Medicine, Aristotle University of Thessaloniki, Thessaloniki, Greece \\ ${ }^{2}$ Department of Psychiatry and Psychotherapy, Technical University of Munich, School of Medicine, Munich, Germany \\ ${ }^{3}$ 1st Department of Psychiatry, Medical School, Aiginition Hospital, National \& Kapodistrian University of Athens, Athens, \\ ${ }^{4}$ Unit of Social Psychiatry \& Psychosocial Care, University Mental Health, Neurosciences and Precision Medicine Research Institute \\ "Costas Stefanis" (UMHRI), Athens, Greece \\ ${ }^{5}$ Department of Health Services Policy and Management, Arnold School of Public Health, University of South Carolina, Columbia, SC \\ ${ }^{6}$ Department of Social and Education Policy, School of Social and Political Sciences, Corinth, Greece \\ ${ }^{7}$ Health Policy Institute, Athens, Greece
}

ARTICLE HISTORY: Received 7 June 2021/Revised 13 September 2021/Published Online 26 November 2021

\begin{abstract}
The impact of the COVID-19 pandemic on the mental health of healthcare professionals is currently under research and prevalence of mental health symptoms across the world vary a lot. Moreover, knowledge and perceptions of healthcare professionals towards the new coronavirus is yet to be explored since very few data have been published to date. Thus, we decided to conduct a cross-sectional, web-based survey to measure the levels of depressive, anxiety and stress symptoms using the Depression, Anxiety and Stress Scale-21. The knowledge and perceptions of healthcare professionals towards the new coronavirus were also examined with a self-constructed questionnaire. Data were collected between April 19th and May 31st 2020. In total, 1484 professionals participated in the survey and 1064 completed it in full; $60.8 \%$ were females, $66.5 \%$ were physicians and $24.3 \%$ were first-line healthcare workers. The prevalence of at least moderate symptoms was $13 \%$ for depression, $11.9 \%$ for anxiety, and $11.3 \%$ for stress. Women, younger participants, residents in urban areas, having lower income and worse self-reported health status had higher scores in all outcomes. First-line healthcare workers also indicated higher anxiety scores compared to those who were not first responders. Regarding knowledge and perceptions, most participants agreed with the asymptomatic nature of the virus and its heightened danger for older individuals and those with underlying health conditions. Different views were expressed regarding the possibility of airborne transmission, its similarity to common flu, and the statements that the new coronavirus is manufactured and serves a specific purpose and that it is out of control. In conclusion, the results of our study suggest that the prevalence of depressive, anxiety and stress symptoms in Greek healthcare professionals is placed in the lower end of the range reported from various recent studies across the world. Nevertheless, professionals at risk should be monitored closely and supported when needed.
\end{abstract}

KEYWORDS: Mental health impact, healthcare workers, depression, anxiety, stress, coronavirus.

Corresponding author: Myrto T. Samara, Aristotle University of Thessaloniki, 1 Kiriakidi street, GR-546 21 Thessaloniki, Greece • e-mail: myrtosamara@auth.gr 


\section{Introduction}

WHO declared a pandemic on March 11 th and suggested strict transmission control measures such as quarantine ${ }^{1}$ and social distancing. ${ }^{2}$ During this time, hospitals in highly affected areas were already overcrowded and healthcare workers overwhelmed by the increased workload, constrained hospital capacity and inability to cure patients and the fear of contracting and transmitting the infection to others, a situation expected to cause severe psychological distress. ${ }^{3-7}$ But even in places with low numbers of reported cases, videos and reports from hospitals around the world overflowing with patients with a non-negligible fatality ratio ${ }^{8}$ predisposed healthcare professional to a worstcase scenario.

Research on the impact of the COVID-19 pandemic on the well-being of healthcare professionals is currently emerging. Most of the studies have been undertaken in China, ${ }^{9}$ and fewer in Italy, ${ }^{10}$ Singapore, ${ }^{11}$ Spain, ${ }^{12}$ and Turkey. ${ }^{13}$ The majority of them reported a high prevalence of depressive, anxiety and insomnia symptoms in healthcare professionals, consonant with meta-analyses of early evidence. ${ }^{9,14-16}$

In contrast, research on knowledge and perceptions of healthcare professionals towards the new coronavirus is yet to be explored. Knowledge and perceptions can affect implementation of preventive strategies, identification of suspected cases and quality of information provided to the public. A single relevant study found insufficient level of healthcare workers' knowledge, especially regarding transmission mode and time to symptom onset, ${ }^{17}$ raising important concerns for public health authorities.

In Greece, the first case of the new coronavirus was reported on February 26th and, by the end of August 2021 , the number of confirmed cases exceeded 581,315 with more than 13,581 deaths. ${ }^{18}$ To date, few studies have assessed the impact of the pandemic on the mental health of healthcare workers in Greece, ${ }^{19-21}$ whereas none explored the knowledge and perceptions of this professional group towards the new virus and their possible association with mental health symptoms.

Therefore, the aim of our study was to explore: (1) prevalence of depressive, anxiety, and stress symptoms in healthcare professionals during the pandemic; (2) level of knowledge and perceptions towards the new virus; (3) association of various sociodemographic, occupational and health-related characteristics with mental health symptoms; and (4) association of knowledge and perceptions with mental health symptoms.

\section{Material and Method}

\section{Participants}

This was a cross-sectional, web-based survey designed to obtain information on the psychological and mental health impact of the coronavirus pandemic among Greek healthcare professionals and to assess their knowledge and perceptions. Data were collected between April 19th and May 31st, through an online questionnaire distributed via social media and targeted e-mails, using the snowball technique. In particular, emails were sent to various professional associations of health workers, e.g., Panhellenic Medical Association, inviting them to distribute the survey to their members. All healthcare professionals such as physicians, nurses, pharmacists, and ambulance paramedics were eligible to participate. The study was approved by the Ethics Committee of the University of the Peloponnese and was performed in accordance with the ethical standards delineated in the Declaration of Helsinki 1964/2013.

\section{Measures}

Questionnaire included: (i) sociodemographic and health-related characteristics, (ii) mental health symptoms, and (iii) knowledge and perceptions towards the current virus. Sociodemographic, occupational and health-related characteristics included gender, age, area of residence, type of healthcare profession, whether the responded was a first-line healthcare worker or not, education, weekly working-hours, income, marital status, number of household members, presence of underage children in the household, vulnerability to the virus of the responder or a household member, self-reported health status, smoking and alcohol use. Mental health symptoms were measured using the self-reported Depression, Anxiety and Stress Scale (DASS-21) 22,23 which has been validated for the Greek population and used in previous work. ${ }^{24,25}$ The DASS-21 includes three constructs, each of which ranges from 0 to 42 points: the Depression subscale, the Anxiety subscale and the Stress subscale. Based on cut-off scores, there are four different severity labels for each subscale (mild, moderate, severe, extremely severe).

As for healthcare professionals' knowledge and perceptions towards the current virus, we asked participants six questions related to (i) the asymptomatic nature of the coronavirus, (ii) the coronavirus being dangerous for those who have an underlying disease and are older, (iii) the coronavirus being out of control, (iv) the coronavirus being engineered and serving a purpose, (v) the coronavirus being like a flu, and (vi) the coronavirus being airborne. Respondents were asked to indicate whether they agree or not with each sen- 
tence on a 5-point Likert scale (1=Strongly disagree; $5=$ Strongly agree). The items were self-constructed and resonated with existing evidence about the coronavirus, as reported by the World Health Organization as well as with similar instruments in international literature (e.g. 26, 27).

\section{Statistical analysis}

We initially conducted a descriptive analysis to explore the sociodemographic, occupational and health-related characteristics of the study participants. We then similarly analyzed respondents' knowledge and perceptions related to the new coronavirus and the DASS-21 scores for the Depression, Anxiety, and Stress constructs. Finally, we used multivariate negative binomial regressions to estimate the association between respondents' knowledge and perceptions and the three DASS-21 constructs. We used a negative binomial regression model due to the non-normal distribution (right-skew) of the three outcomes which ranged from 0 to $42 .{ }^{28}$ We used Akaike's Inclusion Criteria (AIC) to evaluate the choice of the negative binomial regression over alternative count models (i.e. Poisson, zero-inflated count models), which confirmed the choice of this model. We also included and accounted for all sociodemographic, occupational and health-related characteristics included in the descriptive analyses. Finally, we used geographic-level fixed effects and clustered standard errors at the geographical region of residence to control for unobserved time-invariant regional variation. Incidence rate ratios (IRR) and their $95 \%$ confidence intervals (95\% $\mathrm{Cl}$ ) were calculated. An alpha level of $p=.05$ was used for significance testing. Participants with missing data were excluded from the analysis. Data were collected in Excel and all statistical analyses were conducted using Stata (version 16.1; StataCorp, College Station, TX).

\section{Results}

Response rate and sociodemographic, occupational and health-related characteristics of respondents

In total, 1484 healthcare professionals participated in the survey and 1064 completed it in full (response rate: $71.7 \%)$. The majority were females, aged 40 to 54 years (table 1). Area of residence was balanced between urban and suburban areas. More than half were medical staff, with tertiary or post-tertiary education level. About one-quarter (24.3\%) were first-line healthcare workers and $39.4 \%$ of participants worked 40 to 45 hours per-week. Most participants reported average or higher-than average income, while only $7.6 \%$ indicated low or very low income. $67.4 \%$ of participants were
Table 1. Sociodemographic, occupational and health-related characteristics of respondents.

\begin{tabular}{|c|c|}
\hline & $\begin{array}{c}\text { Participants } \\
(\mathrm{n}=1064)\end{array}$ \\
\hline \multicolumn{2}{|l|}{ Gender (\%) } \\
\hline Male & 39.2 \\
\hline Female & 60.8 \\
\hline \multicolumn{2}{|l|}{ Age categories (\%) } \\
\hline 18 to 39 & 27.8 \\
\hline 40 to 54 & 52.7 \\
\hline 55 or more & 19.5 \\
\hline \multicolumn{2}{|l|}{ Place of Residence (\%) } \\
\hline Urban & 50.8 \\
\hline Non-urban & 49.2 \\
\hline \multicolumn{2}{|l|}{ Healthcare Profession } \\
\hline Medical staff & 66.5 \\
\hline Nursing staff & 10.4 \\
\hline Pharmacist & 7.6 \\
\hline Other & 15.4 \\
\hline \multicolumn{2}{|l|}{ First-line healthcare worker } \\
\hline No & 75.7 \\
\hline Yes & 24.3 \\
\hline \multicolumn{2}{|l|}{ Education (\%) } \\
\hline Post-tertiary (Masters/Doctoral) & 43.2 \\
\hline Tertiary & 48.1 \\
\hline High School & 8.7 \\
\hline \multicolumn{2}{|l|}{ Weekly working hours (\%) } \\
\hline More than 50 & 15.9 \\
\hline 46 to 50 & 14.5 \\
\hline 40 to 45 & 39.4 \\
\hline Less than 40 & 30.3 \\
\hline \multicolumn{2}{|l|}{ Income (\%) } \\
\hline Higher than average & 40.7 \\
\hline Average & 43.3 \\
\hline Low to Average & 8.4 \\
\hline Low/Very low & 7.6 \\
\hline \multicolumn{2}{|l|}{ Marital status (\%) } \\
\hline Married/Living together & 67.4 \\
\hline Not married & 23.7 \\
\hline Divorced/Widowed & 8.9 \\
\hline Number of people in household & $2.9(1.5)$ \\
\hline \multicolumn{2}{|l|}{ Underage children in household (\%) } \\
\hline No & 54.4 \\
\hline Yes & 45.6 \\
\hline
\end{tabular}


Table 1. (Continued).

\begin{tabular}{ll}
\hline & \multicolumn{1}{c}{$\begin{array}{c}\text { Participants } \\
(\mathrm{n}=1064)\end{array}$} \\
\hline $\begin{array}{l}\text { Respondent is vulnerable to COVID due } \\
\text { to underlying health problem (\%) }\end{array}$ & \\
$\quad$ No & 20.3 \\
Yes & \\
Household member is vulnerable & \\
to COVID due to underlying health & \\
problem (\%) & \\
$\quad$ No & 69.6 \\
Yes & 30.4 \\
Perceived health status (\%) & \\
Very good & 28.8 \\
Good & 51.7 \\
Medium & 16.3 \\
Ver bad/bad & 3.2 \\
Smoker (\%) & \\
No & 68.0 \\
Yes & 32.0 \\
Alcohol use (regular) (\%) & \\
No & 90.4 \\
Yes & 9.6 \\
\hline
\end{tabular}

married. The average household size was $2.9(\mathrm{SD}=1.5)$ individuals and $45.6 \%$ of households included underage children. About one-fifth of respondents indicated that they were vulnerable to the current virus due to an underlying healthcare condition, while $30.4 \%$ reported that a member of their household was vulnerable to the new virus due to an existing health condition. About half deemed their health status as good, while $28.8 \%$ perceived having very good health and only $3.2 \%$ reported having bad or very bad health. About one-third were currently smoking and $9.6 \%$ were regular alcohol users.

\section{Mental health symptoms of participants}

Table 2 presents participants' mental health outcomes. Average scores on the three DASS-21 subscales were $3.32(S D=5.17)$ for anxiety, $9.34(S D=7.99)$ for stress, and $6.37(S D=7.33)$ for depression. Most reported normal scores across all three mental health outcomes; $83.0 \%$ for the anxiety subscale, $80.7 \%$ for the stress subscale, and $74.3 \%$ for the depression subscale. However, $11.9 \%$ of healthcare professionals reported at least moderate anxiety symptoms, $11.3 \%$ reported at least moderate stress symptoms, and $13 \%$ at least moderate depressive symptoms, with 4 to $5 \%$ of participants
Table 2. The Depression, Anxiety and Stress Scale-21 (DASS-21) score of respondents for anxiety, stress, and depression.

\begin{tabular}{ll}
\hline Anxiety & \\
DASS-21 score - average (SD) & $3.32(5.17)$ \\
DASS-21 score (\%) & \\
Normal (0-7) & 83.0 \\
Mild (8-9) & 5.1 \\
Moderate (10-14) & 8.0 \\
Severe (15-19) & 1.8 \\
Extremely Severe (20+) & 2.1 \\
Stress & \\
DASS-21 score - average (SD) & 9.34 (7.99) \\
DASS-21 score (\%) & \\
Normal (0-14) & 80.7 \\
Mild (15-18) & 8.0 \\
Moderate (19-25) & 6.6 \\
Severe (26-33) & 3.0 \\
Extremely Severe (34+) & 1.7 \\
Depression & \\
DASS-21 score - average (SD) & 6.37 (7.33) \\
DASS-21 score (\%) & \\
Normal (0-9) & 74.3 \\
Mild (10-13) & 12.7 \\
Moderate (14-20) & 7.8 \\
Severe (21-27) & \\
Extremely Severe (28+) & \\
\hline & \\
&
\end{tabular}

being identified as having severe or extremely severe anxiety, stress, or depression scores. A robustness statistical check based on the timing of each response was applied, but no change in the results was observed.

\section{Knowledge and perceptions related}

to the new coronavirus

Table 3 presents respondents' knowledge and perceptions related to the new coronavirus. Healthcare professionals almost unanimously agreed with the asymptomatic nature of the virus $(96.1 \%)$ and its heightened danger for older individuals and those with underlying health conditions (92.2\%). More than half perceived that the virus is transmitted by air (58.5\%) while a similar share $(59.5 \%)$ of respondents disagreed with the view that the new coronavirus is manufactured and serves a purpose. Most disagreed with the similarity between coronavirus and common flu (47.7\%), while around one-third (30.0\%) supported the opposite. Finally, while $43.5 \%$ thought the virus is not out of control, $31.4 \%$ were neutral and $25.1 \%$ agreed with this statement. 
Table 3. Respondents' knowledge and perceptions related to the current virus.

\begin{tabular}{|c|c|}
\hline & $\begin{array}{c}\text { Participants } \\
(\mathrm{n}=1064)\end{array}$ \\
\hline \multicolumn{2}{|c|}{ The virus may be asymptomatic (\%) } \\
\hline Agree & 96.1 \\
\hline Neutral & 1.8 \\
\hline Disagree & 2.1 \\
\hline \multicolumn{2}{|c|}{$\begin{array}{l}\text { The virus is dangerous for older people } \\
\text { and for those with underlying health problems (\%) }\end{array}$} \\
\hline Agree & 92.2 \\
\hline Neutral & 2.9 \\
\hline Disagree & 4.9 \\
\hline \multicolumn{2}{|c|}{ The virus is airborne (\%) } \\
\hline Agree & 58.5 \\
\hline Neutral & 15.6 \\
\hline Disagree & 25.9 \\
\hline \multicolumn{2}{|c|}{$\begin{array}{l}\text { The virus is manufactured and serves specific } \\
\text { purposes (\%) }\end{array}$} \\
\hline Agree & 17.0 \\
\hline Neutral & 23.5 \\
\hline Disagree & 59.5 \\
\hline \multicolumn{2}{|c|}{ The virus is similar to common flu (\%) } \\
\hline Agree & 30.0 \\
\hline Neutral & 22.3 \\
\hline Disagree & 47.7 \\
\hline \multicolumn{2}{|c|}{ The virus is out of control (\%) } \\
\hline Agree & 25.1 \\
\hline Neutral & 31.4 \\
\hline Disagree & 43.5 \\
\hline
\end{tabular}

Association between sociodemographic, occupational and health-related characteristics and mental health outcomes

The results of the three multivariate negative binomial regressions for each mental health subscale separately are presented in table 4. Higher scores across all three DASS-21 Anxiety, Stress, and Depression subscales were observed for females, for those who were less than 55 years of age, particularly for those younger than 39 years of age, compared to those who were 55 years or older, and for urban residents. First-line healthcare workers also indicated higher Anxiety scores compared to those who were not first responders. Nursing staff reported lower Depression scores and pharmacists higher Anxiety scores compared to medical staff. Participants with tertiary education had lower scores in the Stress subscale compared to those with post-tertiary edu- cation. Also, scores across all three DASS- 21 subscales tended to be higher for individuals with income lower than those in the 'higher than average' category. Single (unmarried) individuals reported higher scores in the Stress subscales compared to those who were married. As expected, compared to healthcare professionals with very good self-reported health status, those with worse health status ("good", "moderate", "bad/very bad") had consistently higher scores across all three subscales. Systematic alcohol users reported lower Anxiety and higher Depression scores. Increased Anxiety was also observed among healthcare professional whose member of their household was vulnerable to the virus due to underlying health conditions. All other associations were not significant.

\section{Association between respondents' knowledge and perceptions related to the current virus and mental health outcomes}

Lower scores in the Stress subscale were observed for healthcare professionals who disagreed with the asymptomatic nature of the virus as compared to those who supported this statement. Healthcare professionals who agreed with the similarity of the coronavirus with the common flu had lower Anxiety and Stress scores compared to those who reported disagreement. Professionals who were neutral regarding the statement that the current virus is out of control had higher Stress and Depressive scores compared to those who disagreed with this statement. Finally, no other significant association was observed between DASS scores and the remaining examined knowledge and perceptions.

\section{Discussion}

This cross-sectional study evaluated the psychological impact of COVID-19 pandemic on healthcare professionals in Greece, using a large number of participants and various independent characteristics. Moreover, it is the first study to explore the relationship between depressive, anxiety and stress symptoms with knowledge and perceptions of this group towards the new coronavirus.

Healthcare professionals suffer from increased psychological distress, ${ }^{29-31}$ with high rates of psychiatric disorders. ${ }^{32-34}$ Especially during pandemic outbreaks, the exposure of healthcare professionals to stressors is increased. ${ }^{35}$ In our study, $11 \%$ to $13 \%$ of healthcare professionals reported at least moderate depressive, anxiety, and stress symptoms. Prevalence estimates across the world vary a lot and stratified analyses by country cannot so far explain this high heterogeneity. ${ }^{36}$ Our results are placed in the lower end of the prevalence 
276 M.T. Samara et al

Table 4. Multivariate negative binomial regression estimates between DASS- 21 anxiety, stress, and depression scales and respondents' knowledge and perceptions on the virus and their sociodemographic, occupational and health-related characteristics.

\begin{tabular}{|c|c|c|c|c|c|c|c|c|c|c|c|c|}
\hline & \multicolumn{4}{|c|}{ Anxiety } & \multicolumn{4}{|c|}{ Stress } & \multicolumn{4}{|c|}{ Depression } \\
\hline & IRR & $\mathrm{p}$ & $95 \%$ & $\mathrm{Cl}$ & IRR & $\mathrm{p}$ & $95 \%$ & $\mathrm{Cl}$ & IRR & $\mathrm{p}$ & $95 \%$ & $\mathrm{Cl}$ \\
\hline \multicolumn{13}{|c|}{$\begin{array}{l}\text { Sociodemographic, occupa- } \\
\text { tional and health-related } \\
\text { characteristics }\end{array}$} \\
\hline \multicolumn{13}{|l|}{ Gender (Ref: Male) } \\
\hline Female & 1.85 & $<0.001$ & 1.49 & 2.30 & 1.41 & $<0.001$ & 1.18 & 1.68 & 1.43 & $<0.001$ & 1.23 & 1.67 \\
\hline \multicolumn{13}{|l|}{ Age categories (Ref: $\geq 55$ ) } \\
\hline $40-54$ & 1.16 & 0.361 & 0.85 & 1.58 & 1.24 & 0.001 & 1.09 & 1.42 & 1.10 & 0.427 & 0.87 & 1.40 \\
\hline $18-39$ & 1.48 & 0.012 & 1.09 & 2.02 & 1.34 & $<0.001$ & 1.14 & 1.57 & 1.35 & 0.005 & 1.09 & 1.66 \\
\hline \multicolumn{13}{|l|}{$\begin{array}{l}\text { Place of Residence } \\
\text { (Ref: non-urban) }\end{array}$} \\
\hline Urban & 1.35 & 0.019 & 1.05 & 1.73 & 1.27 & $<0.001$ & 1.11 & 1.44 & 1.18 & 0.042 & 1.01 & 1.39 \\
\hline \multicolumn{13}{|l|}{$\begin{array}{l}\text { Healthcare profession } \\
\text { (Ref: Medical staff) }\end{array}$} \\
\hline Nursing staff & 1.01 & 0.946 & 0.77 & 1.32 & 0.89 & 0.284 & 0.72 & 1.10 & 0.85 & 0.034 & 0.73 & 0.99 \\
\hline Pharmacist & 1.61 & 0.004 & 1.17 & 2.22 & 1.18 & 0.071 & 0.99 & 1.41 & 0.93 & 0.527 & 0.74 & 1.17 \\
\hline Other & 0.63 & 0.166 & 0.33 & 1.21 & 0.87 & 0.214 & 0.70 & 1.08 & 0.79 & 0.103 & 0.60 & 1.05 \\
\hline \multicolumn{13}{|l|}{ First-line worker (Ref: No) } \\
\hline Yes & 1.41 & 0.038 & 1.02 & 1.94 & 1.06 & 0.204 & 0.97 & 1.15 & 1.05 & 0.538 & 0.90 & 1.21 \\
\hline \multicolumn{13}{|c|}{ Education (Ref: Post-tertiary) } \\
\hline Tertiary & 0.89 & 0.264 & 0.73 & 1.09 & 0.93 & 0.010 & 0.89 & 0.98 & 0.97 & 0.625 & 0.87 & 1.08 \\
\hline High School & 1.15 & 0.466 & 0.80 & 1.65 & 0.96 & 0.670 & 0.78 & 1.18 & 0.93 & 0.706 & 0.63 & 1.37 \\
\hline \multicolumn{13}{|l|}{$\begin{array}{l}\text { Weekly working hours } \\
\text { (Ref: }>50 \text { ) }\end{array}$} \\
\hline 46 to 50 & 0.87 & 0.346 & 0.65 & 1.16 & 0.93 & 0.228 & 0.83 & 1.04 & 0.97 & 0.800 & 0.77 & 1.22 \\
\hline 40 to 45 & 1.09 & 0.544 & 0.83 & 1.42 & 1.01 & 0.892 & 0.88 & 1.16 & 1.10 & 0.402 & 0.88 & 1.36 \\
\hline Less than 40 & 0.88 & 0.341 & 0.68 & 1.14 & 0.95 & 0.460 & 0.83 & 1.09 & 1.02 & 0.848 & 0.85 & 1.23 \\
\hline \multicolumn{13}{|c|}{$\begin{array}{l}\text { Income } \\
\text { (Ref: Higher than average) }\end{array}$} \\
\hline Average & 1.16 & 0.122 & 0.96 & 1.41 & 1.11 & 0.107 & 0.98 & 1.25 & 1.23 & $<0.001$ & 1.12 & 1.36 \\
\hline Low to average & 1.43 & 0.044 & 1.01 & 2.02 & 1.29 & $<0.001$ & 1.15 & 1.45 & 1.44 & $<0.001$ & 1.29 & 1.61 \\
\hline Very low//Low & 1.14 & 0.621 & 0.67 & 1.94 & 1.01 & 0.963 & 0.72 & 1.41 & 1.30 & 0.281 & 0.81 & 2.09 \\
\hline \multicolumn{13}{|c|}{ Marital status (Ref: Married) } \\
\hline Not married & 1.10 & 0.561 & 0.79 & 1.53 & 1.14 & 0.012 & 1.03 & 1.27 & 1.24 & 0.102 & 0.96 & 1.59 \\
\hline Divorced/Widowed & 0.85 & 0.435 & 0.57 & 1.27 & 0.84 & 0.170 & 0.66 & 1.08 & 0.87 & 0.405 & 0.64 & 1.20 \\
\hline \multicolumn{13}{|c|}{$\begin{array}{l}\text { Underage children in house- } \\
\text { hold (Ref:No) }\end{array}$} \\
\hline Yes & 1.05 & 0.807 & 0.72 & 1.53 & 0.99 & 0.874 & 0.84 & 1.16 & 0.94 & 0.419 & 0.80 & 1.10 \\
\hline \multicolumn{13}{|c|}{$\begin{array}{l}\text { Respondent is vulnerable } \\
\text { to COVID due to underlying } \\
\text { health problem (Ref: No) }\end{array}$} \\
\hline Yes & 1.10 & 0.617 & 0.75 & 1.63 & 0.95 & 0.539 & 0.80 & 1.13 & 0.98 & 0.823 & 0.79 & 1.21 \\
\hline \multicolumn{13}{|c|}{$\begin{array}{l}\text { Household member is vulner- } \\
\text { able to COVID due to under- } \\
\text { lying health problem (Ref: No) }\end{array}$} \\
\hline Yes & 1.25 & 0.039 & 1.01 & 1.56 & 1.03 & 0.559 & 0.93 & 1.15 & 1.02 & 0.723 & 0.90 & 1.16 \\
\hline
\end{tabular}


Table 4. (Continued).

\begin{tabular}{|c|c|c|c|c|c|c|c|c|c|c|c|c|}
\hline & \multicolumn{4}{|c|}{ Anxiety } & \multicolumn{4}{|c|}{ Stress } & \multicolumn{4}{|c|}{ Depression } \\
\hline & IRR & $\mathrm{p}$ & $95 \%$ & $\mathrm{Cl}$ & IRR & $\mathrm{p}$ & $95 \%$ & $\mathrm{Cl}$ & IRR & $\mathrm{p}$ & $95 \%$ & $\mathrm{Cl}$ \\
\hline \multicolumn{13}{|c|}{$\begin{array}{l}\text { Perceived health status } \\
\text { (Ref: Very good) }\end{array}$} \\
\hline Good & 1.81 & $<0.001$ & 1.32 & 2.49 & 1.34 & $<0.001$ & 1.19 & 1.51 & 1.32 & $<0.001$ & 1.18 & 1.48 \\
\hline Moderate & 2.54 & $<0.001$ & 1.77 & 3.64 & 1.68 & $<0.001$ & 1.36 & 2.08 & 1.89 & $<0.001$ & 1.38 & 2.59 \\
\hline Very bad/bad & 2.30 & $<0.001$ & 1.48 & 3.57 & 1.61 & 0.002 & 1.19 & 2.19 & 2.54 & $<0.001$ & 1.67 & 3.87 \\
\hline \multicolumn{13}{|l|}{ Smoker (Ref: No) } \\
\hline Yes & 1.16 & 0.320 & 0.87 & 1.55 & 1.11 & 0.147 & 0.97 & 1.27 & 1.12 & 0.231 & 0.93 & 1.33 \\
\hline \multicolumn{13}{|c|}{ Alcohol use-regular (Ref: No) } \\
\hline Yes & 0.81 & 0.008 & 0.70 & 0.95 & 1.06 & 0.434 & 0.91 & 1.24 & 1.42 & $<0.001$ & 1.24 & 1.62 \\
\hline \multicolumn{13}{|c|}{ Knowledge and perceptions } \\
\hline \multicolumn{13}{|c|}{$\begin{array}{l}\text { The virus may be asymptomatic } \\
\text { (Ref: Agree) }\end{array}$} \\
\hline Neutral & 1.14 & 0.673 & 0.62 & 2.08 & 1.00 & 0.988 & 0.66 & 1.54 & 0.74 & 0.457 & 0.34 & 1.62 \\
\hline Disagree & 0.96 & 0.875 & 0.57 & 1.61 & 0.63 & 0.006 & 0.45 & 0.87 & 0.84 & 0.448 & 0.54 & 1.32 \\
\hline \multicolumn{13}{|c|}{$\begin{array}{l}\text { The virus is dangerous for older } \\
\text { people and for those } \\
\text { with underlying health problems } \\
\text { (Ref: Agree) }\end{array}$} \\
\hline Neutral & 0.97 & 0.860 & 0.65 & 1.43 & 1.11 & 0.632 & 0.73 & 1.70 & 1.43 & 0.115 & 0.92 & 2.24 \\
\hline Disagree & 1.03 & 0.885 & 0.66 & 1.61 & 1.10 & 0.643 & 0.73 & 1.65 & 1.03 & 0.890 & 0.67 & 1.58 \\
\hline \multicolumn{13}{|c|}{ The virus is airborne (Ref: Disagree) } \\
\hline Neutral & 0.89 & 0.240 & 0.74 & 1.08 & 0.98 & 0.758 & 0.88 & 1.09 & 1.05 & 0.602 & 0.87 & 1.28 \\
\hline Agree & 0.91 & 0.422 & 0.71 & 1.15 & 0.92 & 0.214 & 0.82 & 1.05 & 0.94 & 0.343 & 0.83 & 1.06 \\
\hline \multicolumn{13}{|c|}{$\begin{array}{l}\text { The virus is manufactured and serves } \\
\text { specific purposes (Ref: Disagree) }\end{array}$} \\
\hline Neutral & 1.14 & 0.372 & 0.85 & 1.54 & 1.11 & 0.065 & 0.99 & 1.24 & 1.16 & 0.113 & 0.97 & 1.40 \\
\hline Agree & 0.97 & 0.625 & 0.85 & 1.10 & 1.07 & 0.270 & 0.95 & 1.21 & 0.91 & 0.147 & 0.80 & 1.03 \\
\hline \multicolumn{13}{|c|}{$\begin{array}{l}\text { The virus is similar to common flu } \\
\text { (Ref: Disagree) }\end{array}$} \\
\hline Neutral & 1.20 & 0.193 & 0.91 & 1.57 & 1.02 & 0.778 & 0.90 & 1.15 & 1.06 & 0.395 & 0.93 & 1.21 \\
\hline Agree & 0.74 & $<0.001$ & 0.62 & 0.87 & 0.85 & 0.003 & 0.76 & 0.95 & 0.90 & 0.218 & 0.76 & 1.07 \\
\hline \multicolumn{13}{|c|}{$\begin{array}{l}\text { The virus is out of control (Ref: } \\
\text { Disagree) }\end{array}$} \\
\hline Neutral & 1.02 & 0.815 & 0.84 & 1.25 & 1.08 & 0.023 & 1.01 & 1.16 & 1.18 & 0.001 & 1.07 & 1.30 \\
\hline Agree & 1.24 & 0.057 & 0.99 & 1.54 & 1.06 & 0.144 & 0.98 & 1.14 & 1.12 & 0.206 & 0.94 & 1.33 \\
\hline
\end{tabular}

Notes: All regression models control for geographic-level fixed effects; DASS-21: Depression, Anxiety and Stress Scale-21; IRR: Incidence Rate Ratio; Cl: Confidence Intervals

range reported from various recent studies ${ }^{9,36}$ which could be explained by the low infection and death rate in Greece at that time, similarly to other countries like Singapore which reported even lower DASS-21 scores. ${ }^{11}$ Nevertheless, these estimates are much lower than other studies in Greek healthcare professionals during the same period of time: Pappa et al found that approximately one third of frontline healthcare professionals reported at least moderate depression, anxiety and traumatic stress; ${ }^{19}$ Kalaitzaki and Rovithis assessed the secondary traumatic stress and found that almost $80 \%$ of healthcare professionals suffered from at least moderate secondary stress; ${ }^{20}$ and Alexopoulos et al reported increased severity of anxiety symptoms in back- 
stage and frontline hospital workforce (27\% and $45 \%$ respectively), but this was not the case for the severity of depressive symptoms ( $15 \%$ and $12 \%$ respectively). ${ }^{21}$ Alternatively, it may be the case that healthcare professionals are under a continuously increased psychological burden. ${ }^{37}$ Identified risk factors such as female gender, younger age, being a first-line healthcare worker, living in urban areas, having lower income and worse self-reported health status agree with the literature. ${ }^{38}$

As for the respondents' knowledge and perceptions towards the new coronavirus, the vast majority acknowledged that the virus may be asymptomatic and that it is dangerous for older people and for those with underlying health problems. Furthermore, almost two thirds of respondents agreed with its airborne transmission although this topic was still controversial among researchers by that time with some data supporting this mode of transmission, ${ }^{39-41}$ while other studies did not. ${ }^{42-44}$ Moreover, more than half of respondents agreed or were neutral towards the statements that the virus is similar to common flu and that it is out of control. Both these statements are open to various interpretations. COVID-19 and influenza (flu) are both contagious respiratory illnesses, caused by RNA viruses, and share many similarities like symptoms, transmission routes, characteristics of people at high risk for severe illness, and complications. ${ }^{45}$ Despite the similarities, there are also important differences between the two like the possibility of airborne transmission route, ${ }^{46}$ of higher spread $^{47}$ and death rate ${ }^{8}$ for COVID-19, and the availability of approved vaccines and antiviral drugs for the prevention and treatment of flu. These differences became apparent in our findings where healthcare professionals who supported the similarity between COVID-19 and the common flu exhibited lower rates across all three mental health outcomes. Comparably, the statement that the virus is out of control could be considered ambiguous. On the one hand, WHO reports almost everyday record daily increases in coronavirus cases worldwide ${ }^{18}$ despite sounding global alarm months ago; on the other hand, countries like Singapore and Greece, when strict preventive and/or containment measures were imposed, managed to control it.

Last but not least, approximately $40 \%$ of respondents agreed or were neutral towards the statement that the virus is manufactured and serves specific purposes. A positive correlation has been shown between conspiracy beliefs and unwillingness to follow guidelines and engage in health-protective behaviors, ${ }^{48-51}$ highlighting the important implications of these findings for individuals and society. Comparable rates of endorsement of conspiracy beliefs regarding the cause of the virus were reported by a study in the general public in $\mathrm{UK}^{52}$ but the prevalence reported in our study is even more worrisome as it refers to healthcare professionals who are supposed to be more knowledgeable, follow guidelines and inform the public. High levels of anxiety and stress have been proposed as causative of conspiracy beliefs. ${ }^{53}$ Interestingly, in our study, no difference in any of mental health outcomes was shown for professionals who endorsed or refuted this specific conspiracy belief. Similarly, a recent study in the general public found no relationship between COVID-19 conspiracy beliefs and self-reported stress. ${ }^{54}$ These results imply that belief in conspiracy theories is a more complex phenomenon and numerous factors may underlie it such as personality traits, individual characteristics like educational level and political ideology, a need to feel safe and to maintain a positive image, source of information, and belief in previous conspiracy theories..$^{53,55}$ To the best of our knowledge and despite the emerging literature on the impact of the coronavirus pandemic, this is the first study examining the prevalence of a common conspiracy belief about the cause of the virus among healthcare professionals.

In our analysis, broad inclusion criteria were applied since all workers relevant to the provision of healthcare such as physicians, nurses, pharmacists, and ambulance paramedics were eligible to participate. To enhance participation in our study, social media pages targeting healthcare professionals were used and emails via relevant professional associations were sent. In our final sample, more than half of participants were physicians and no difference in any of the mental health outcomes between the various healthcare professions was observed. Nevertheless, many other reports on the topic have identified increased severity of psychological symptoms in nurses, ${ }^{9,15}$ possibly because of the direct and intense contact with patients and increased risk of contagion. A possible explanation for not corroborating this finding in the present study could be the low number of nurses in the sample, which increased the possibility of failing to detect a difference although it might be present (type 2 error).

Owing to many limitations, our results are not conclusive. Firstly, participants were not randomly selected from the population of healthcare professionals and the self-selection process applied might be associated with specific personality, mental-health or other individual characteristics that could not be identified, quantified and adjusted for; therefore, selection bias might exist and the sample cannot be considered representative. Furthermore, the cross-sectional design of our study, with no follow-up data, could be affected by the timing of data collection. As the epidemic evolves, the mental health impact on healthcare professionals might 
also change depending on severity of each epidemic phase, medical developments, and emergency measures imposed by the state. The time period covered by the present study was extended, i.e., 6 weeks, which allowed for a robustness statistical check based on the timing of each response, but no change in the results was observed. Moreover, the use of self-reported questionnaires rather than face-to-face diagnostic assessments by mental health professionals has itself a number of disadvantages such as social desirability bias, response bias, honesty and interpretation of the questions. Finally, the assessment of many other psychological symptoms like insomnia, self-harm behaviors and post-traumatic stress symptoms was not included.

\section{References}

1. World Health Organisation. Considerations for quarantine of individuals in the context of containment for coronavirus disease (COVID-19): interim guidance. World Health Organisation 2020 (Cited 19 March 2020). Available from: https://www.who.int/publications/i/item/considerations-for-quarantine-of-individuals-in-the-context-of-containment-for-coronavirus-disease-(covid-19)

2. World Health Organisation. Coronavirus disease (COVID-19) advice for the public. World Health Organisation 2021 (Cited 1 October 2021). Available from: https://www.who.int/emergencies/diseases/ novel-coronavirus-2019/advice-for-public

3. Bukhari EE, Temsah MH, Aleyadhy AA, Alrabiaa AA, Alhboob AA, Jamal $\mathrm{AA}$, et al. Middle East respiratory syndrome coronavirus (MERS-CoV) outbreak perceptions of risk and stress evaluation in nurses. $J$ Infect Dev Ctries 2016, 10:845-850, doi: 10.3855/jidc.6925

4. Chen CS, Wu HY, Yang P, Yen CF. Psychological distress of nurses in Taiwan who worked during the outbreak of SARS. Psychiatr Serv 2005 , 56:76-79, doi: 10.1176/appi.ps.56.1.76

5. Liu X, Kakade M, Fuller CJ, Fan B, Fang Y, Kong J, et al. Depression after exposure to stressful events: lessons learned from the severe acute respiratory syndrome epidemic. Compr Psychiatry 2012, 53:15-23, doi: 10.1016/j.comppsych.2011.02.003

6. Matsuishi K, Kawazoe A, Imai H, Ito A, Mouri K, Kitamura N, et al. Psychological impact of the pandemic (H1N1) 2009 on general hospital workers in Kobe. Psychiatry Clin Neurosci 2012, 66:353-360, doi: 10.1111/j.1440-1819.2012.02336.x

7. Maunder RG, Lancee WJ, Balderson KE, Bennett JP, Borgundvaag B, Evans $S$, et al. Long-term psychological and occupational effects of providing hospital healthcare during SARS outbreak. Emerg Infect Dis 2006, 12:1924-1932, doi: 10.3201/eid1212.060584

8. Faust JS, Del Rio C. Assessment of Deaths From COVID-19 and From Seasonal Influenza. JAMA Intern Med 2020, 180:1045-1046 doi: 10.1001/jamainternmed.2020.2306.

9. Luo M, Guo L, Yu M, Jiang W, Wang $H$. The psychological and mental impact of coronavirus disease 2019 (COVID-19) on medical staff and general public - A systematic review and meta-analysis. Psychiatry Res 2020, 291:113190, doi: 10.1016/j.psychres.2020.113190

10. Rossi R, Socci V, Pacitti F, Di Lorenzo G, Di Marco A, Siracusano A, et al. Mental Health Outcomes Among Frontline and Second-Line Health Care Workers During the Coronavirus Disease 2019 (COVID-19) Pandemic in Italy. JAMA New Open 2020, 3:e2010185, doi: 10.1001/ jamanetworkopen.2020.10185
In conclusion, protecting mental health of healthcare professionals is crucial for safeguarding the provision of sustainable healthcare services, especially during pandemic outbreaks. Our analysis suggests that being female and young, living in urban areas, and having lower income and worse self-reported health status increase the risk of adverse mental health outcomes. Thus, professionals with such characteristics should be monitored closely and supported when needed. Furthermore, online trainings, targeted campaigns and simulation exercises should be provided to healthcare professionals to improve their knowledge and perceptions and enable them to make informed choices based on the best available evidence at any given time.

11. Tan BYQ, Chew NWS, Lee GKH, Jing M, Goh Y, Yeo LLL et al. Psychological Impact of the COVID-19 Pandemic on Health Care Workers in Singapore. Ann Intern Med 2020, 173:317-320, doi: 10.7326/M20-1083

12. Garcia-Fernandez L, Romero-Ferreiro V, Lopez-Roldan PD, Padilla S, Calero-Sierra I, Monzo-Garcia M, et al. Mental health impact of COVID-19 pandemic on Spanish healthcare workers. Psychol Med 2020, 1-3, doi: 10.1017/S0033291720002019

13. Elbay RY, Kurtulmus A, Arpacioglu S, Karadere E. Depression, anxiety, stress levels of physicians and associated factors in Covid-19 pandemics. Psychiatry Res 2020, 290:113130, doi: 10.1016/j.psychres.2020.113130

14. Kisely S, Warren N, McMahon L, Dalais C, Henry I, Siskind D. Occurrence, prevention, and management of the psychological effects of emerging virus outbreaks on healthcare workers: rapid review and meta-analysis. BMJ 2020, 369:1642, doi: 10.1136/bmj.m1642

15. Pappa S, Ntella V, Giannakas T, Giannakoulis VG, Papoutsi E, Katsaounou P. Prevalence of depression, anxiety, and insomnia among healthcare workers during the COVID-19 pandemic: A systematic review and meta-analysis. Brain Behav Immun 2020, doi: 10.1016/j.bbi.2020.05.026

16. Vindegaard N, Eriksen Benros M. COVID-19 pandemic and mental health consequences: Systematic review of the current evidence. Brain Behav Immun 2020, doi: 10.1016/j.bbi.2020.05.048

17. Bhagavathula AS, Aldhaleei WA, Rahmani J, Mahabadi MA, Bandari DK. Knowledge and Perceptions of COVID-19 Among Health Care Workers: Cross-Sectional Study. JMIR Public Health Surveill 2020, 6:e19160, doi: $10.2196 / 19160$

18. Worldometers. COVID-19 coronavirus pandemic 2020. Available from: https://www.worldometers.info/coronavirus/

19. Pappa S, Athanasiou N, Sakkas N, Patrinos S, Sakka E, Barmparessou $Z$, et al. From Recession to Depression? Prevalence and Correlates of Depression, Anxiety, Traumatic Stress and Burnout in Healthcare Workers during the COVID-19 Pandemic in Greece: A Multi-Center, Cross-Sectional Study. Int J Environ Res Public Health 2021, 18, doi: 10.3390/ijerph18052390

20. Kalaitzaki A, Rovithis M. Secondary traumatic stress and vicarious posttraumatic growth in healthcare workers during the first COVID-19 lockdown in Greece: The role of resilience and coping strategies. Psychiatriki 2021, 32:19-25, doi: 10.22365/jpsych.2021.001

21. Alexopoulos P, Roukas D, Efkarpidis A, Konstantopoulou G, Soldatos $\mathrm{R}$, Karaivazoglou $\mathrm{K}$, et al. Hospital workforce mental reaction to the pandemic in a low COVID-19 burden setting: a cross-sectional clinical study. Eur Arch Psychiatry Clin Neurosci 2021, doi: 10.1007/s00406-02101262-y

22. Lovibond PF, Lovibond SH. The structure of negative emotional states: comparison of the Depression Anxiety Stress Scales (DASS) 
with the Beck Depression and Anxiety Inventories. Behav Res Ther 1995, 33:335-343, doi: 10.1016/0005-7967(94)00075-u

23. Henry JD, Crawford JR. The short-form version of the Depression Anxiety Stress Scales (DASS-21): construct validity and normative data in a large non-clinical sample. Br J Clin Psychol 2005, 44:227-239, doi: 10.1348/014466505X29657

24. Lyrakos GN, Arvaniti C, Smyrnioti M, Kostopanagiotou G. P03-561Translation and Validation Study of the Depression Anxiety Stress Scale in the Greek General Population and in a Psychiatric Patient's Sample. European Psychiatry 2011, 26:1731, doi: 10.1016/S0924-9338(11)73435-6

25. Pezirkianidis C, Karakasidou E, Lakioti A, Stalikas A, Galanakis M. Psychometric Properties of the Depression, Anxiety, Stress Scales-21 (DASS-21) in a Greek Sample. Psychology 2018, 9:2933-2950, doi: 10.4236/psych.2018.915170

26. Zhong BL, Luo W, Li HM, Zhang QQ, Liu XG, Li WT et al. Knowledge, attitudes, and practices towards COVID-19 among Chinese residents during the rapid rise period of the COVID-19 outbreak: a quick online cross-sectional survey. Int J Biol Sci 2020, 16:1745-1752, doi: 10.7150/ ijbs. 45221

27. Wang C, Pan R, Wan X, Tan Y, Xu L, Ho CS, et al. Immediate Psychological Responses and Associated Factors during the Initial Stage of the 2019 Coronavirus Disease (COVID-19) Epidemic among the General Population in China. Int J Environ Res Public Health 2020, 17, doi: 10.3390/ijerph17051729

28. Long JS, Freese J. Regression Models for Categorical Dependent Variables using Stata. 2nd ed. StataCorp LP, 2006

29. Aasland OG, Olff M, Falkum E, Schweder T, Ursin H. Health complaints and job stress in Norwegian physicians: the use of an overlapping questionnaire design. Soc Sci Med 1997, 45:1615-1629, doi: 10.1016/ s0277-9536(97)00093-2

30. Hardy GE, Shapiro DA, Borrill CS. Fatigue in the workforce of National Health Service Trusts: levels of symptomatology and links with minor psychiatric disorder, demographic, occupational and work role factors. J Psychosom Res 1997, 43:83-92, doi: 10.1016/s0022-3999(97)00019-6

31. Tholdy Doncevic S, Romelsjo A, Theorell T. Comparison of stress, job satisfaction, perception of control, and health among district nurses in Stockholm and prewar Zagreb. Scand J Soc Med 1998, 26:106-114, doi: 10.1177/14034948980260021001

32. Hannan E, Breslin N, Doherty E, McGreal M, Moneley D, Offiah G. Burnout and stress amongst interns in Irish hospitals: contributing factors and potential solutions. Ir J Med Sci 2018, 187:301-307, doi: 10.1007/ s11845017-1688-7

33. Shanafelt TD, Hasan O, Dyrbye LN, Sinsky C, Satele D, Sloan J et al. Changes in Burnout and Satisfaction With Work-Life Balance in Physicians and the General US Working Population Between 2011 and 2014. Mayo Clin Proc 2015, 90:1600-1613, doi: 10.1016/j.mayocp.2015.08.023

34. Zhou C, Shi L, Gao L, Liu W, Chen Z, Tong X et al. Determinate factors of mental health status in Chinese medical staff: A cross-sectional study. Medicine (Baltimore) 2018, 97:e0113, doi: 10.1097/MD.000000 0000010113

35. Preti E, Di Mattei V, Perego G, Ferrari F, Mazzetti M, Taranto P et al. The Psychological Impact of Epidemic and Pandemic Outbreaks on Healthcare Workers: Rapid Review of the Evidence. Curr Psychiatry Rep 2020, 22:43, doi: 10.1007/s11920-020-01166-z

36. Phiri $P$, Ramakrishnan $R$, Rathod S, Elliot K, Thayanandan T, Sandle N, et al. An evaluation of the mental health impact of SARS-CoV-2 on patients, general public and healthcare professionals: A systematic review and meta-analysis. EClinicalMedicine 2021, 34:100806, doi: 10.1016/j.eclinm.2021.100806

37. Dutheil F, Aubert C, Pereira B, Dambrun M, Moustafa F, Mermillod M, et al. Suicide among physicians and health-care workers: A systematic review and meta-analysis. PLoS One 2019, 14:e0226361, doi: 10.1371/ journal.pone.0226361
38. Uphoff EP, Lombardo C, Johnston G, Weeks L, Rodgers M, Dawson $S$ et al. Mental health among healthcare workers and other vulnerable groups during the COVID-19 pandemic and other coronavirus outbreaks: A rapid systematic review. PLoS One 2021, 16:e0254821, doi: 10.1371/journal.pone.0254821

39. Rahmani AR, Leili M, Azarian G, Poormohammadi A. Sampling and detection of corona viruses in air: A mini review. Sci Total Environ 2020, 740:140207, doi: 10.1016/j.scitotenv.2020.140207

40. Guo ZD, Wang ZY, Zhang SF, Li X, Li L, Li C, et al. Aerosol and Surface Distribution of Severe Acute Respiratory Syndrome Coronavirus 2 in Hospital Wards, Wuhan, China, 2020. Emerg Infect Dis 2020, 26:15831591, doi: 10.3201/eid2607.200885

41. Razzini K, Castrica M, Menchetti L, Maggi L, Negroni L, Orfeo NV, et al. SARS-CoV-2 RNA detection in the air and on surfaces in the COVID-19 ward of a hospital in Milan, Italy. Sci Total Environ 2020, 742:140540, doi: 10.1016/j.scitotenv.2020.140540

42. Ong SWX, Tan YK, Chia PY, Lee TH, Ng OT, Wong MSY, et al. Air, Surface Environmental, and Personal Protective Equipment Contamination by Severe Acute Respiratory Syndrome Coronavirus 2 (SARS-CoV-2) From a Symptomatic Patient. JAMA 2020, 323:1610-1612, doi: 10.1001/ jama.2020.3227

43. Cheng VC, Wong SC, Chan VW, So SY, Chen JH, Yip CC, et al. Air and environmental sampling for SARS-CoV-2 around hospitalized patients with coronavirus disease 2019 (COVID-19). Infect Control Hosp Epidemiol 2020, 1-8, 10.1017/ice.2020.282

44. Wu S, Wang Y, Jin X, Tian J, Liu J, Mao Y. Environmental contamination by SARS-CoV-2 in a designated hospital for coronavirus disease 2019 Am J Infect Control 2020, 48:910-914, doi: 10.1016/j.ajic.2020.05.003

45. Centers for Disease Control and Prevention, National Center for Immunization and Respiratory Diseases (NCIRD). Similarities and Differences between Flu and COVID-19. Centers for Disease Control and Prevention (CDC) 2021 (Cited 7 June 2021). Available from: https:// www.cdc.gov/flu/symptoms/flu-vs-covid19.htm

46. Morawska L, Milton DK. It is Time to Address Airborne Transmission of COVID-19. Clin Infect Dis 2020, 71:2311-2313, doi: 10.1093/cid/ciaa939

47. Sanche S, Lin YT, Xu C, Romero-Severson E, Hengartner N, Ke R. High Contagiousness and Rapid Spread of Severe Acute Respiratory Syndrome Coronavirus 2. Emerg Infect Dis 2020, 26:1470-1477, doi: 10.3201/eid2607.200282

48. Dunn AG, Surian D, Leask J, Dey A, Mandl KD, Coiera E. Mapping information exposure on social media to explain differences in HPV vaccine coverage in the United States. Vaccine 2017, 35:3033-3040, doi: 10.1016/j.vaccine.2017.04.060

49. Goertzel T. Conspiracy theories in science. EMBO Rep 2010, 11:493-499, doi: 10.1038/embor.2010.84

50. Jolley D, Douglas KM. The effects of anti-vaccine conspiracy theories on vaccination intentions. PLoS One 2014, 9:e89177, doi: 10.1371/ journal.pone.0089177

51. Grebe E, Nattrass N. AIDS conspiracy beliefs and unsafe sex in Cape Town. AIDS Behav 2012, 16:761-773, doi: 10.1007/s10461-011-9958-2

52. Freeman D, Waite F, Rosebrock L, Petit A, Causier C, East A, et al. Coronavirus conspiracy beliefs, mistrust, and compliance with government guidelines in England. Psychol Med 2020, 1-13, doi: 10.1017/ S0033291720001890

53. van Prooijen JW, Douglas KM. Belief in conspiracy theories: Basic principles of an emerging research domain. Eur J Soc Psychol 2018 48:897-908, doi: 10.1002/ejsp.2530

54. Georgiou N, Delfabbro P, Balzan R. COVID-19-related conspiracy beliefs and their relationship with perceived stress and pre-existing conspiracy beliefs. Pers Individ Dif 2020, 166:110201, doi: 10.1016/j. paid.2020.110201

55. Douglas KM, Sutton RM, Cichocka A. The Psychology of Conspiracy Theories. Curr Dir Psychol Sci 2017, 26:538-542, doi: 10.1177/0963 721417718261 


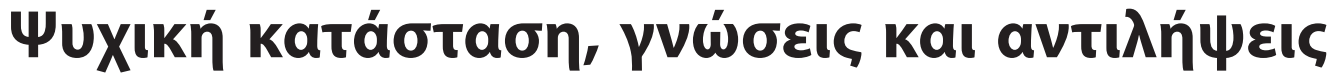

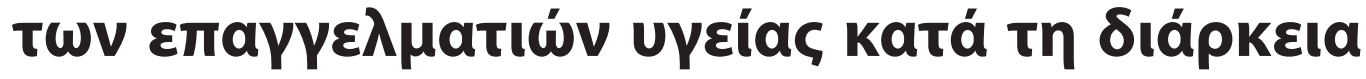

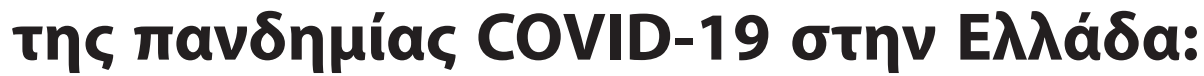

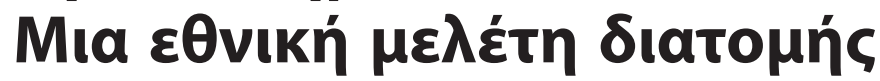

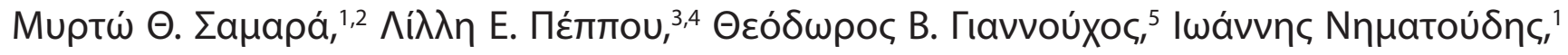

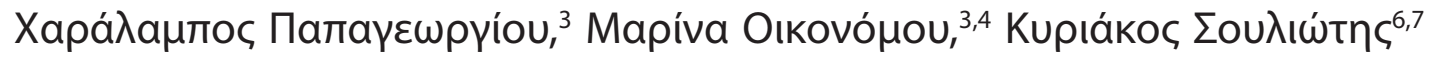

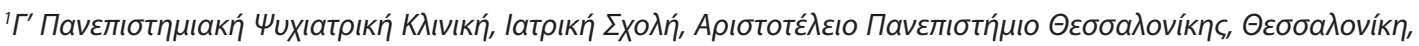

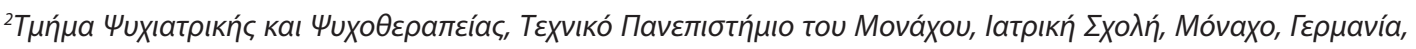

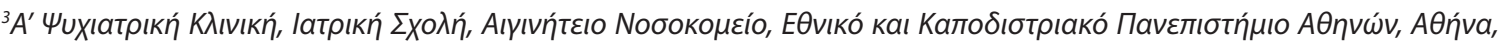

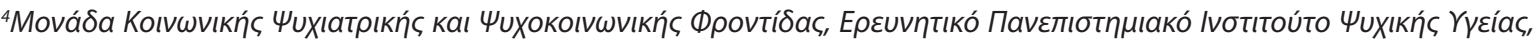

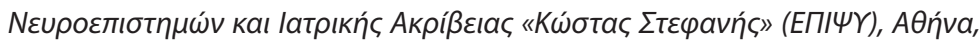

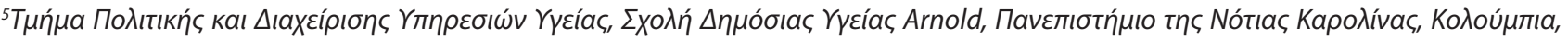 \\ Nótıa Kapoגíva,

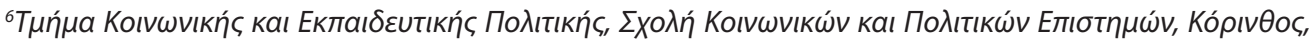

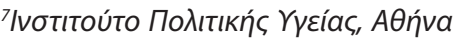

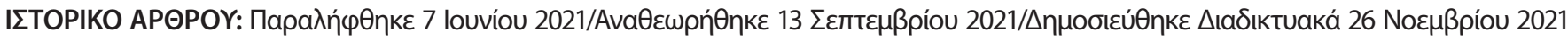

\section{ПЕРІ^НЧН}

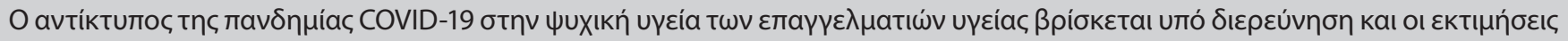

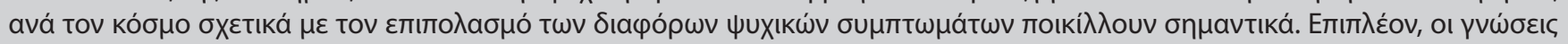

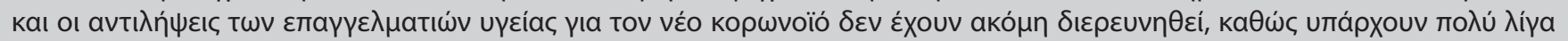

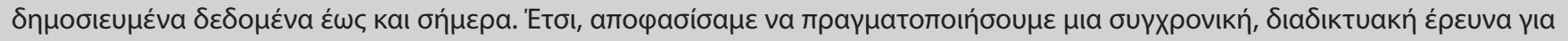

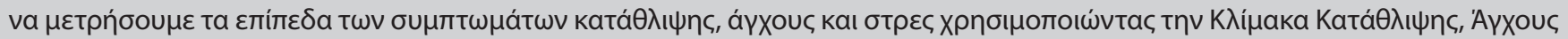

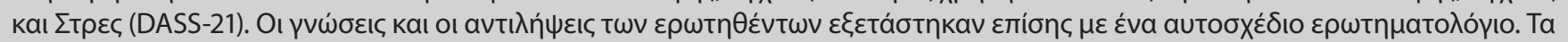

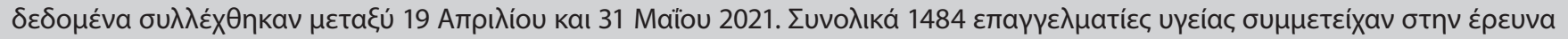

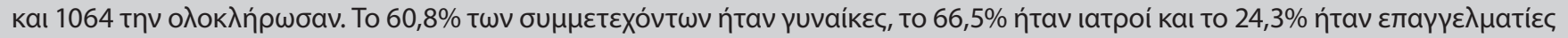

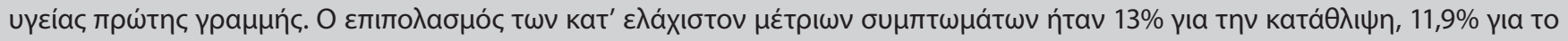

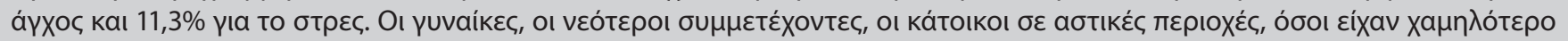

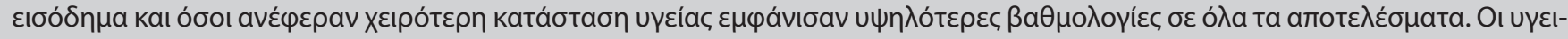

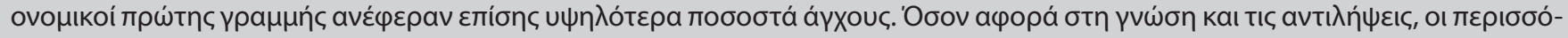

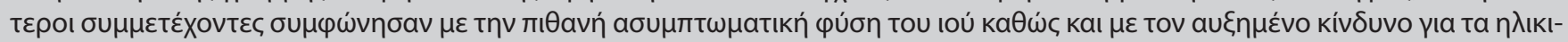

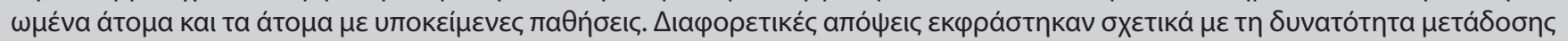

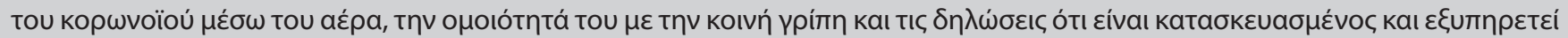

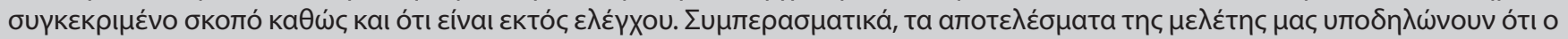

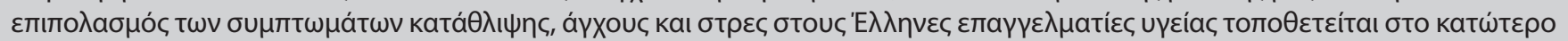

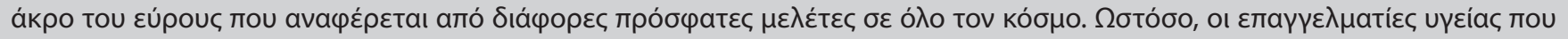

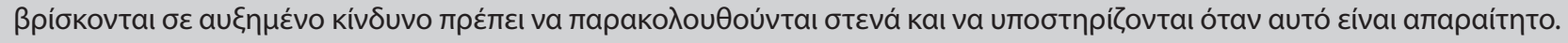

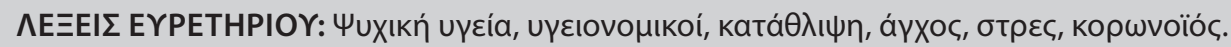

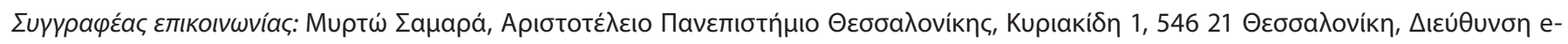
mail:myrtosamara@auth.gr 